\title{
REVIEW
}

\section{VEGETATION IMPACT ON THE DUNE STABILITY AND FORMATION ON THE LITHUANIAN COAST OF THE BALTIC SEA}

\author{
Ramunè URBONIENÉa ${ }^{a}$, Loreta KELPŠAITÉb ${ }^{b}$ Ingrida BORISENKO ${ }^{c}$ \\ ${ }^{a}$ Landscape Architecture and Environmental Planning, Klaipeda University, Herkaus Manto g. 84, \\ LT-92294 Klaipeda, Lithuania \\ ${ }^{b}$ Geophysical Department, Klaipèda University, Herkaus Manto g. 84, LT-92294 Klaipéda, Lithuania \\ ${ }^{c}$ Computer Science Department, Klaipéda University, Herkaus Manto g. 84, LT-92294 Klaipéda, Lithuania
}

Submitted 24 Mar. 2014; accepted 14 Jan. 2015

\begin{abstract}
The aim of this study was to estimate vegetation coverage impact on the sandy beach and protective beach dune ridge (PBD) formation. Studies of the Lithuanian Baltic Sea coastal morphometric parameters and vegetation coverage projection were carried out from 1999 to 2011. In order to evaluate the dependence of the beach and the PBD morphometric parameters on the projection of vegetation coverage changes, correlation analyses were performed. A very strong link between vegetation projection coverage of the PBD top and beach width and incline of the eastern slope of $\mathrm{PBD}$, and western slope vegetation projection coverage with the incline of the western slope of $\mathrm{PBD}$ were observed. A strong correlation relationship was observed between vegetation projection coverage of the PBD top and width of the PBD top. A medium relationship was noted between vegetation projection coverage of the PBD top with the width of the eastern slope. A negative relationship was noticed between the PBD western slope vegetation projection coverage and beach width.

It may be admitted that the projection coverage of vegetation may be used as PBD's parameter of stability as well as in the implementation of integrated coastal zone management.
\end{abstract}

Keywords: beach, vegetation, sand dune, environmental sustainability.

\section{Introduction}

Beaches are formed by waves, currents and tidal action, with waves generally being the predominant force. Within the surf zone, deep water waves begin to interact with the seabed. These result in changes in the direction and height of the incoming waves, which tend to align themselves in a direction parallel to the shoreline. Depending on the actual direction from which these waves approach, sand or other material may be transferred along the coast or in an onshore/offshore direction, or in a combination of both (Komar 1998). Dunes form when sand is carried by the wind from a beach towards the land. Although most sand particles are moved by saltation, surface creep may account for $20-25 \%$ of the moved sand. Transplanting vegetation will not prevent erosion, but it will accelerate recovery after storm damage by creating a trap for sand within the fore-dunes. This makes the dunes better able to survive the following period of erosion. Dune vegetation promotes the large-scale trapping of sand. The stems of dune grasses reduce the wind velocity near the surface, causing deposition of sand. Plant roots also serve to bind and consolidate the sand. Dune grasses thrive on incoming sand and accelerate their growth to keep up with the increasing height of the dune. The vegetation coverage represents the difference between a mobile pile of sand and a stabilized dune (Boak, Turner 2005; Stallins 2005).

Unfortunately, sand dunes, like wetlands, have been perceived as "useless" areas and their many functions, such as sand reserves for the beach and protection for land areas from harmful salt laden winds have been little understood (Komar 1998; Heslenfeld et al. 2004; Maun 2004).

Vegetation is one of the most important environmental factors which forms the beach and protects the beach

Corresponding author: Ramunè Urbonienè

E-mail: ramune.uo@gmail.com 
dune ridge on sandy coastlines. Dense vegetation coverage protects the coast against erosion caused by the eolian processes (Vilà et al. 2007; Isermann 2008), and human activities (Provoost et al. 2002). Dunes overgrow with various herbs, which are typical for the sandy coastline. This includes the Honckenya peploides (L.) Ehrh., Cakile baltica Jord. ex. Pobed., Ammophila arenaria (L.) Link., Leymus arenarius (L.) Hochst., which are stable, however, a very important parameter is the projection coverage of vegetation and species composition of plant communities (Fontana 2005; Łabuz 2007; Hilton, Konlechner 2011).

A vegetation communities analysed at the Baltic seaside of Lithuania are attributed to the complex of vegetation of the sands Ammophiletum arenariae Br.-Bl. et R. Tx. 1943 of the white dunes. It consists of plants growing in unfavorable meteorological conditions on the free-flowing sand constantly being blown and which also has a low amount of nutritious materials. The order Ammophiletalia arenariae $\mathrm{Br}$ - $\mathrm{Bl} .1933$ is represented by one row, which combines primary communities of the white dunes, while the Ammophila arenaria of different development levels of the white dunes belong to the union. Communities prevalent on the coastline of the Baltic Sea according to the growing conditions and species composition are attributed to the association Leymo-Ammophiletum arenariae $\mathrm{Br}$.- $\mathrm{Bl}$. et De Leeuw 1936 (Stankevičiūtè 2006).

Seaside flora not only depends on natural and anthropogenic environmental factors, but they also affect the microclimate and soil of a specific region (Remke, Blindow 2011). On the sand dunes, the natural change of the plant communities is that they are growing; however, their progress is disturbed at places by the artificial reinforcement of dunes, beautification processes and recreational activity. Sufficient plant cover protects fragile dunes against: wind erosion by decreasing wind speed at ground level and by providing a protective cover over the dune; reduce but not prevent damage from wave erosion; build up sand dunes and thereby increase the sand reserve for storm waves. Dune vegetation has the ability to regenerate naturally after storm damage and facilitate natural dune recovery (NSW 2001). The aim of this study is to identify the impact of sandy beach and PBD vegetation coverage on their morphometric parameters in the south-eastern Baltic Sea region.

\section{Materials and methods}

\subsection{Study area}

The south-eastern Baltic Sea coast (Lithuanian coastal zone) covers $90.6 \mathrm{~km}$ of beach and PBD ridge along the whole western side of the sea coast of the Curonian Spit and mainland coast (Fig. 1). The length of the dune ridge at the Curonian Spit is about $51.01 \mathrm{~km}$. The mainland coast's morphologically is more diverse: the beach and its protective dune ridge covers $38.42 \mathrm{~km}$, including moraine cliff, cascading sand cliffs $(5.62 \mathrm{~km})$ and natural coastal dunes $(3.73 \mathrm{~km})$ (Jarmalavičius et al. 2012a). The intensive change of meteorological conditions and effects, which impacts the change of beach and PBD indicators, is constantly taking place on the Baltic Sea coast of Lithuania. Moreover, intensive anthropogenic activity, which unevenly affects the analysed territory, is taking place here as well (Žilinskas, Jarmalavičius 2007; Povilanskas et al. 2009; Jarmalavičius et al. 2012b).

The first article related to PBD formation and the protection of the Curonian Spit (SE Baltic Sea coast) was published by S. Biörn, 1807. Further PBD regulation works were described in several German scientists' works at the end of $19^{\text {th }}$ century (Stankevičiūte 2006).

The need to create PBD at the Curonian Spit became evident between the fifteenth and nineteenth century. During that time, a number of settlements were established along the Curonian Lagoon, seeking protection from the Baltic winds behind the high dunes. Only a few small areas remained forested by the end of the eighteenth century. A natural low PBD in the Southern part of the Curonian Spit (width of the spit $\sim 700 \mathrm{~m}$ ) wasn't sufficient to protect the beach during storms, and the Baltic Sea water would pass along the PBD to the Curonian Lagoon. Further north, free masses of sand evoke dune migrations and a number of Curonian villages were buried (Buynevich et al. 2007). In 1807, under the S. Biörn initiative the work of the forming and planting of the protective foredune was commenced at a settlement in Southern section of the $\mathrm{Cu}$ ronian Spit seashore to curb the sand drift and the seas reaching the plains beyond the dunes. The introduction of woody and grassy plants to the drifting sand of Nida and its approaches were started in 1825 under the initiative of G. D. Kuvert. That work of forming and planting the protective dune in the Curonian Spit was finished in 1904.
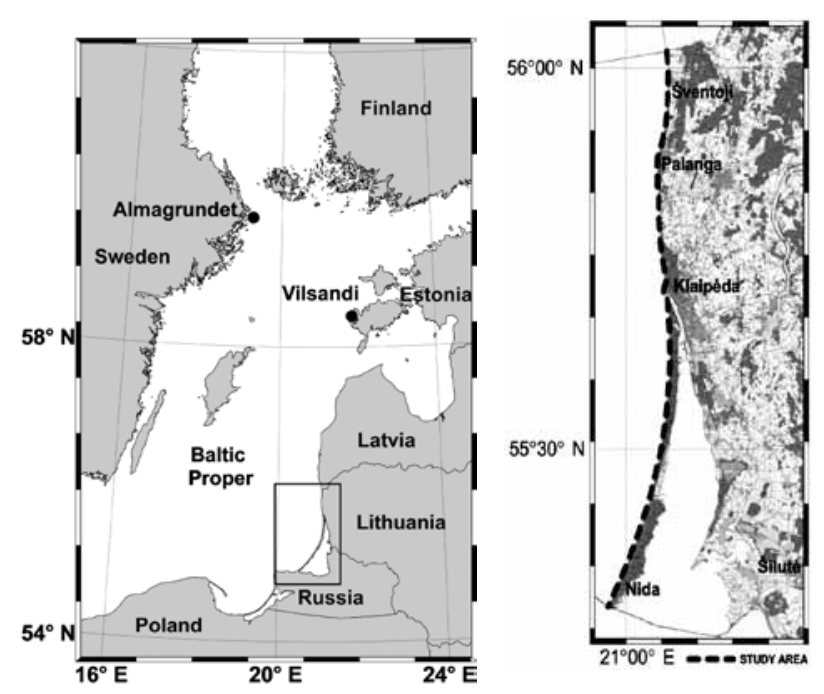

Fig. 1. Map of field sides 
The protective dune supervision is being continued to this day (Olšauskas 2009).

\subsection{Characteristics of the research area}

The studies of coastline's morphometric parameters and projection coverage of vegetation were carried out during the 1999-2011 period. While evaluating long-term data of the water level on the Lithuanian coast, it can be suggested that the lowest rise in the total annual water level (only $2 \%$ ) is in August and the water level is equal or close to "zero" of the perennial water level (Dailidienè et al. 2006).

Measurements of the cross profiles of the beach and PBD (in total 139 profiles, Fig. 1) were made in each 500$1000 \mathrm{~m}$ from the state border with the Republic of Latvia to the border with the Russian Federation (Kaliningrad region), following recommendations for measurement of heights and distances provided in the work of Skeivalas (2001) (Fig. 2).

The following parameters of the beach and PBD were measured: the beach width and height $(\mathrm{m})$, the width and height of the PBD western slope $(\mathrm{m})$, the top width $(\mathrm{m})$, and the width and height of the eastern slope $(\mathrm{m})$. Beach: the beach incline $\left(^{\circ}\right)$, the incline of the western slope $\left({ }^{\circ}\right)$, and the incline of the eastern slope $\left(^{\circ}\right)$ were calculated from the width and height data. The theodolite (T-30 (N 12511)) was used for the beach profiling. If there was a need to measure additional distance to the supplementary points, the calibrated tape-measure $(50 \mathrm{~m})$ was used (see Fig. 2).

\subsection{Vegetation research description}

During the last 200 years there have been various reforestation programs for the outer coastal regions, with the aim of establishing a proper vegetation coverage and protecting settlement combined with a reduction in soil erosion and sand dune movement (Savukynienè et al. 2003). While undertaking research on morphometric parameters of the beach and PBD, research on the projection coverage of vegetation was also carried out. The vegetation coverage

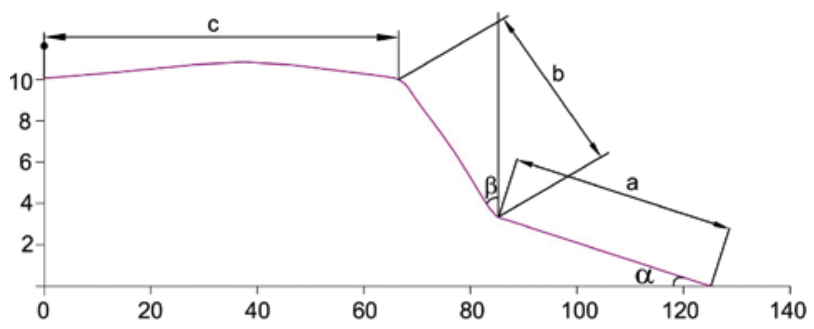

Fig. 2. Layout of the profile measurement

Note: Distances: $\mathrm{a}$ - beach width; $\mathrm{b}$ - width of the western slope of the protective beach dune ridge; $c$ - width of the top of the protective beach dune ridge. Distances are measured using a calibrated roulette and expressed in meters. Inclines measured in degrees: $\alpha$-beach incline, $\beta$ - incline of the western slope of the protective beach dune ridge. research was carried out at the site in a $4 \times 4 \mathrm{~m}$ area. This area was chosen due to the fact that the seacoast sand plant communities are located in a mosaic way and take up a small area. In order to carry out a more detailed analysis of the projection coverage of vegetation on the PBD, research on vegetation in all profiles was carried out across the PBD - that is, on the western slope and on the top and on the eastern slope. Descriptions of the plant communities of the PBD were made by applying French-Swiss principles (that of the Zurich-Montpellier school) principles for the vegetation research. Latin names of plants are provided based on inventories of botanical names. To evaluate the abundance and cover of species of vegetation communities, the Braun-Blanquet scale was used (Walker et al. 2004). The projection coverage of grassy plants has been estimated according to 10 gradation of covering ( 0 , $10,20,30 \ldots 100 \%$ of the investigating area).

The coverage and abundance of vegetation at the sites is evaluated as a percentage using the frame divided into 25 small squares, each of which conforms to $4 \%$ of the total coverage. Firstly, coverage of each species of plant is fixed in each square; later on, after counting them, the total coverage of each species of plants at the site is received. For systematic analysis of flora, the system of vascular plants made by Gudžinskis (1999) was used. Vascular plants were described according to Snarskis (1968) and Lekavičius (1989). More detailed description of the procedure is described at Olšauskas, Urbonienè (2009).

\subsection{Statistical data analysis}

To evaluate the obtained morphometric parameters of the PBD and the results of the vegetation research, a statistical analysis was carried out using $\mathrm{R}$ software package. To analyse the data, a correlation analysis was made.

Correlation analysis. The correlation analysis was made to indicate an impact of the analysed factors on the parameters and interrelationship intensity between the parameters. To evaluate the relationship cohesion between variables, Pearson's correlation rate is most often used:

$$
r=\frac{\sum_{i=1}^{n}\left(x_{i}-\bar{x}\right)\left(y_{i}-\bar{y}\right)}{(n-1) s_{x} s_{y}} ;
$$

where: $x_{i}$ and $y_{i}$ - values of the sample of the variables; $y$ and $x$ - the average values of the sample of these variables; $s_{x}$ and $s_{y}$ - standard tolerances of the variables; $n$ - the number of pairs of the variable values (Mukaka 2012). In the correlation regressive analysis, the independent (cause) variable is marked as $x$ and the dependent (output) variable is marked as $y$.

Pearson's correlation coefficient may be applied only in the case of linear and close-to-linear dependence when the variables are distributed under the 
Gaussian distribution. If these conditions are not met, Spearman's correlation coefficient is used for assessment of cohesion of relationship between the variables. Pearson's correlation coefficient, as well as Spearman's, may have values in the range $[-1,1]$. Dependence (relationship between the variables) is as strong as it is close to the value of the correlation coefficient of 1 or -1 . Positive value shows that there is positive (direct) dependence between the variables, and vice versa a negative (inverse) dependence. In statistical literature, different scales for evaluation of the correlation coefficient are provided. In this work, the following interpretation of values of the correlation coefficient was used:

- 0.00-0.19 - very poor relationship;

- 0.20-0.39 - weak relationship;

- 0.40-0.69- medium relationship;

- 0.70-0.89 - strong relationship;

- 0.90-1.00 - very strong interrelationship.

Even if there is no dependence between the variables, the correlation coefficient calculated based on the sample data will hardly be equal to zero. Thus, in the case of low values of the correlation coefficient (let's say $r<$ 0.2 ), the question arises whether non-equality of the correlation coefficient to zero is accidental (Mukaka 2012). When evaluating the reliability of the correlation coefficient $r$ (statistical significance) and the existence of the relationship between the analysed variables, hypotheses $\mathrm{H}_{0}: \mathrm{R}=0, \mathrm{H}_{1}: \mathrm{R} \neq 0$ is being checked and Student's distribution is used. When using the statistical package in the calculations, it is suggested that the correlation coefficient is reliable when the calculated p (Sig. (2-tailed)) < 0.05 (hereafter 0.05 is the default significance level used in the work).

\section{Results and discussion}

\subsection{Analysis of vegetation and species composition's projection coverage}

The western slope of the protective beach dune ridge is affected by visitors, prevailing winds and during storms by waves. Ammophila arenaria and Leymus arenarius can be found on the dune, which is closest to the shoreline. It has been noticed that Gypsophila paniculata L., Lathyrus maritimus (L.) Bigelow also appears on the seaside dune part further to the dune top. Growing this species stabilizes the structure which traps sand being blown by the wind from the sea to the coast. They also dominate at the dune foot and in that way constitute a convenient environment for other species which occur further on in the dune. Ammophila arenaria and Leymus arenarius prefer dry and low-nutritious sandy soils, and tolerate saline sandy soils. Together with the Gypsophila paniculata and Lathyrus maritimus they form coastal sand dunes and stabilize sand drifting (Fontana 2005; Hilton,
Konlechner 2011; Lucas, Carter 2013). Plants with their powerful root system make matts of various densities, well reinforcing the PBD and in this way reducing the sand transfer (Stankevičiūte 2006; Olšauskas, Urboniene 2009). On the western edge of the PBD beside Leymus arenarius, Ammophila arenaria, Gypsophila paniculata and Lathyrus maritimus there appears to be Calamagrostis epigejos (L.) Roth. These plants resist drought, strong wind and the flow of visitors.

On the top and eastern slope of the PBD there are mainly plants sensitive to intense sand movement which grow there, such as Festuca sabulosa H. Lindb., Tragopogon heterospermus Schweigg, Hieracium umbellatum L., Pilosella officinarum F. W. Schultz et Sch. Bip., Viola littoralis Spreng., Linaria loeselli Schweigg., Carex arenaria L., Lathyrus maritimus and Corynephorus canescens (L.) P. Beauv. It should be noticed that Eryngium maritimum L. appears only in the Nida-Pervalka (Curonian Spit) area. The sandy soil of the eastern slope of the PBD contains larger amount of humus than the western side. It is also the lee side for the stormy Western and Northwestern winds, and it is characterized by a steeper slope in the dune ridge. All these components create a favorable environment to the Jasione montana L., Artemisia campestris L., Carex arenaria, Lathyrus maritimus and Gypsophila paniculata, and also in the Curonian Spit Eryngium maritimum and some other species.

Plants growing on the beach and PBD may be divided into four groups:

- Plants "building" a PBD - Ammophila arenaria, Leymus arenarius, Cakile maritima L, Honckenya peploides and Agropyron dasyanthum Lebed. These plants form the fore-dune and grow on the foot of the western slope of the PBD.

- Plants which tolerate carrying up of the sand and stabilize the PBD - Lathyrus maritimus, Carex arenaria, Calamagrostis epigeios, Gypsophila paniculata, Eryngium maritimum and Petasines spurius (Retz.) Reichb. These plants grow on and stabilize the western slope of the PBD and the western part of the dune top.

- Plants which do not tolerate carrying up of the sand and stabilize the top of the protective beach dune ridge, including Festuca areniaria L., Corynephorus canescens, Tragopogon heterospermus, Hieracium umbellatum, Hieracium pilosella L., Viola littoralis, Linaria loeselii, Artemisia campestris L., Jasione montana L., Thymus serpillius L., Trifolium arvense L., Carex arenaria and Lathyrus maritimus. These plants stabilize the eastern part of the top and the eastern slope of the PBD.

- Plants that tolerate the beach visitors. These are plant species which form a favorable environment for leisure (plants with a soft over-ground part): 
Lathyrus maritimus, Gypsophila paniculata, Petasites spurius, Tragopogon heterospermus, Viola littoralis, Jasione montana and Thymus serpillius.

\subsection{Impact of the $P B D$ vegetation projection coverage on the PBD morphometric parameters}

In order to evaluate the dependence of morphometric parameters of the beach and its PBD on the projection coverage of vegetation, in the 1999-2011 time period correlation analysis was done. It was assumed that the analysed variables distributed according to a Gaussian distribution. After carrying out the analysis between projections coverage of vegetation and morphometric parameters of the research object, the Pearson correlation coefficient and the significance value were calculated (Table 1).

Table 1. The linear correlation relationships between the vegetation projection coverage and the beach morphometric parameters (made by the authors)

\begin{tabular}{|c|c|c|c|c|}
\hline $\begin{array}{l}\text { Dependent } \\
\text { variable }\end{array}$ & $\begin{array}{l}\text { Independent } \\
\text { variable }\end{array}$ & $\mathrm{R}$ & $\begin{array}{c}\text { Equation of linear } \\
\text { dependence }\end{array}$ & $\mathrm{R}^{2}$ \\
\hline Beach width & $\begin{array}{l}\text { Vegetation of } \\
\text { the PBD top }\end{array}$ & 0.69 & $y=21.70+0.73 x$ & 0.480 \\
\hline $\begin{array}{l}\text { Width of the } \\
\text { PBD top }\end{array}$ & $\begin{array}{l}\text { Vegetation of } \\
\text { the PBD top }\end{array}$ & 0.66 & $y=6.68+0.26 x$ & 0.436 \\
\hline $\begin{array}{l}\text { Width of the } \\
\text { eastern slope } \\
\text { of PBD }\end{array}$ & $\begin{array}{l}\text { Vegetation of } \\
\text { the PBD top }\end{array}$ & -0.64 & $y=20.85-0.02 x$ & 0.407 \\
\hline $\begin{array}{l}\text { Incline of } \\
\text { the eastern } \\
\text { slope of } \\
\text { PBD }\end{array}$ & $\begin{array}{l}\text { Vegetation of } \\
\text { the PBD top }\end{array}$ & 0.64 & $y=14.55+0.13 x$ & 0.412 \\
\hline $\begin{array}{l}\text { Width of } \\
\text { the western } \\
\text { slope of PBD }\end{array}$ & $\begin{array}{l}\text { Vegetation of } \\
\text { the western } \\
\text { slope of PBD }\end{array}$ & 0.90 & $y=7.94+0.23 x$ & 0.806 \\
\hline $\begin{array}{l}\text { Incline of } \\
\text { the western } \\
\text { slope of PBD }\end{array}$ & $\begin{array}{l}\text { Vegetation of } \\
\text { the western } \\
\text { slope of PBD }\end{array}$ & -0.93 & $y=57.55-1.41 x$ & 0.872 \\
\hline Beach width & $\begin{array}{l}\text { Vegetation of } \\
\text { the western } \\
\text { slope of PBD }\end{array}$ & -0.51 & $y=52.97-0.37 x$ & 0.256 \\
\hline
\end{tabular}

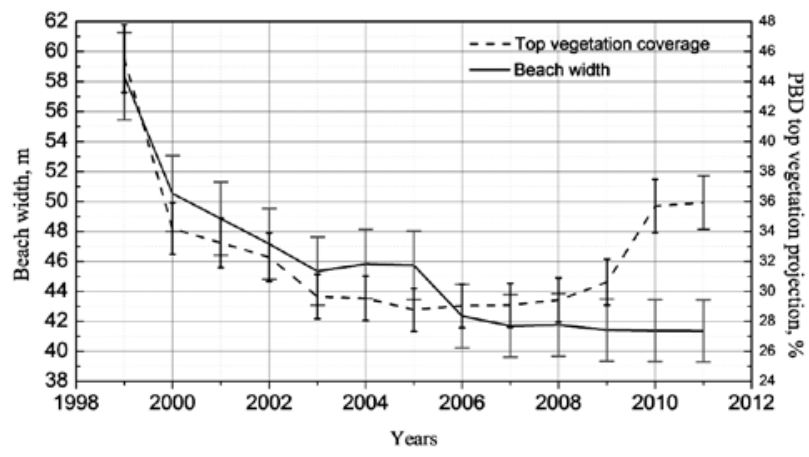

Fig. 3. Changes of beach width and PBD top vegetation coverage
It is noticeable that a very strong relationship is associated with an abundance of vegetation at the western slope and the width of the western slope of PBD. While an abundance of vegetation on the western slope is associated with the incline of the western slope with strong negative relationship. A medium correlation relationship is associated with a richness of vegetation on the top and the (i) beach width, (ii) width of the PBD top and (iii) incline of the eastern slope of PBD. It has been noticed that there is inverse dependence with medium correlation between the richness of vegetation on the PBD top and width of the eastern slope; vegetation of the western slope of PBD and beach width.

Analysis of the calculated values of determination coefficients (Table 1) shows that the change of projection coverage of vegetation on the PBD top impacts on the change of the other PBD sections: by a $48 . \%$ on average value of the beach width, by $43.61 \%$ on width of the PBD top; by the $40 \%$ on width of the eastern slope; by the $41 \%$ on incline of the eastern slope. Changes of projection coverage of vegetation of the western slope of PBD impacts: by $80 \%$ on variation of the width of the western slope; by $87 \%$ on variation of the incline of the western slope of PBD and by $25 \%$ on variation of the width of the beach.

On the PBD's western slope, the plant species Ammophila arenaria, Leymus arenarius, Lathyrus maritimus and Festuca sabulosa mainly occur, which together with other plant species form a stable combination of herbaceous vegetation. This stable combination of vegetation and projection coverage reduce or highly limit the transfer of free sand mass on the western slope of the PBD and other elements of its relief. Therefore, the fore-dune is formed, the width of the beach and the western slope remains stable and the incline of the western slope of the PBD decreases.

Festuca sabulosa, Gypsophila paniculata and Lathyrus maritimus (together with Corynephorus canescens and Ammophila arenaria grow on the top of the western PBD and make a very stable composition of vegetation, which traps the sand on the western part of the PBD and does not allow it to transfer onto the eastern slope. Projection coverage of vegetation and the composition of its species also increases the width of the top as free sand mass is withheld on the top, the sand is not transferred onto the eastern slope, plants growing on it are not covered up and due to that fact the eastern slope is quite stable as well and its width even decreases, while the incline remains unchanged or even increases.

During the analysed period, the beach width decreased on average from $58.3 \mathrm{~m}$ to $41.4 \mathrm{~m}$. The most significant average decrease of the width of the overall beach of Lithuania was after Hurricane Anatoly in 1999 when its width decreased by up to $8 \mathrm{~m}$. At the same 
time PBD top vegetation projection decreased by 8 percentage units in one year (Fig. 3). The distribution of data values, here and further, is represented by showing a single data point, representing the mean value of the data, and error bars to represent the overall distribution of the data. The error bars shown in the line graph above represent a description of how confident you are that the mean represents the true beach width (top vegetation coverage and other parameters) value. In our cases the error bars shows 5 percent positive and negative potential error amounts in the results of a scientific experiment.

From 2000 until 2003, vegetation coverage on the dune top was still decreasing, and later it stabilized. From 2009 to 2010 PBD top vegetation coverage increased by $6 \%$. During the last five years, the beach width has stabilized; this was the result of the increased abundance of vegetation on the PBD top. Correlation regression analysis showed that projection coverage of vegetation of the PBD top and the change of parameters of the beach width depending on it, $(\mathrm{R}=0.69)$, therefore, it may be presumed that in the future the beach width even after strong storms will recover quite quickly as abounding vegetation on the top will trap the transfer of free sand masses.

The average width of the PBD top was not constant and has decreased from 19.5 meters to 13.5 meters (Fig. 4).

The width of the PBD top as well as the beach was destroyed by Hurricane Anatoly in 1999 (Jarmalavičius et al. 2011). Festuca sabulosa, Gypsophila paniculata, Lathyrus maritimus, Corynephorus canescens and other plants growing on the PBD top make a very stable composition, which holds sand on the top. Though the projection coverage of vegetation on the top has decreased from $45 \%$ to $29 \%$ in 9 years, from 2008 the projection coverage of vegetation has been increasing every year. As the free sand masses are more available on the beach, it recovers faster in comparison with the PBD top, where vegetation coverage should first recover. That is noticeable in Figure 4 where PBD top widths become stable just 3 years after a stabilized quantity of vegetation coverage appears. While analysing the projection coverage of vegetation of the PBD top and the change of morphometric parameters of the width of the PBD top depending on the former, a strong correlation $(\mathrm{R}=0.66)$ can be noticed between these two parameters, therefore, it may be presumed that in the future the width of the PBD top will be stable as well.

During the 1999-2011 period, the width of the eastern slope was constant. Its width variations were from 19.9 meters in 1999 to 20.5 meters in 2005. While analysing the projection coverage of vegetation of the PBD top and the change of morphometric parameters of the width of the eastern slope of PBD, a strong inverse correlation $(\mathrm{R}=-0.64)$ was observed; thus, it may be presumed that the width of the eastern slope of the PBD will also remain stable in future and will slightly decrease as increasing vegetation on the top will trap the transfer of free sand masses (Fig. 5).

It was noticed during the research that projection coverage of vegetation of the eastern slope of PBD does not affect the change of the eastern slope of the PBD $(\mathrm{R}=0.23)$.

Regardless the fact that the width of the PBD's eastern slope was changing unevenly, its incline (Fig. 6) during the analysed period was changing evenly and decreased in $\sim 4^{\circ}$, from $21.1^{\circ}$ to $17.8^{\circ}$. The decrease of the incline of the eastern slope of the $\mathrm{PBD}$, as well as the

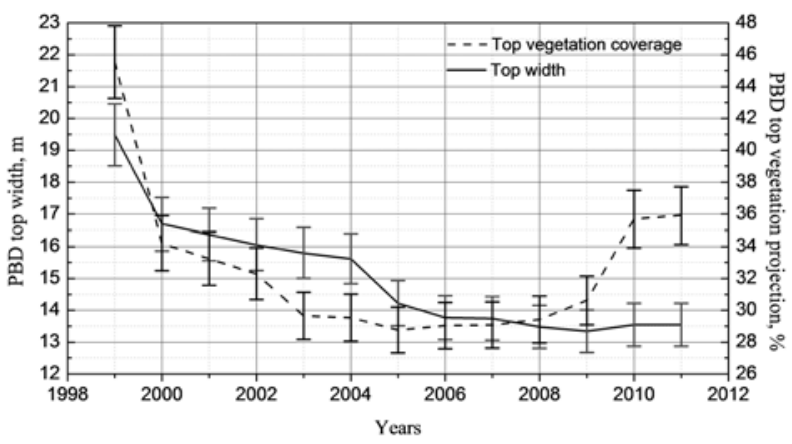

Fig. 4. Changes of PBD top width and vegetation coverage

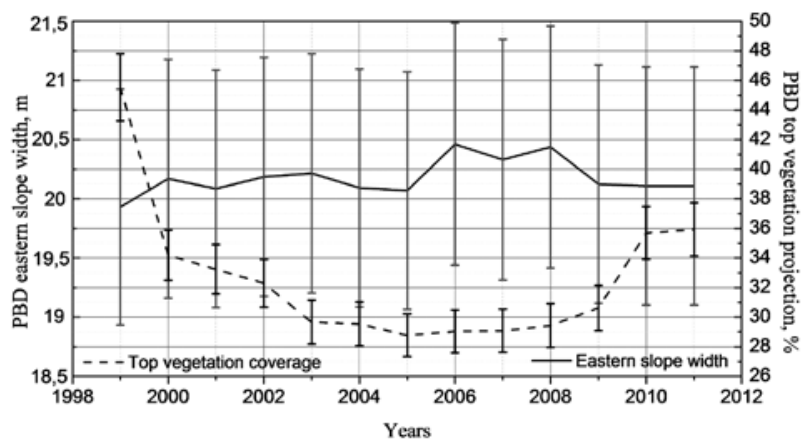

Fig. 5. Changes of PBD eastern slope width and PBD top vegetation coverage

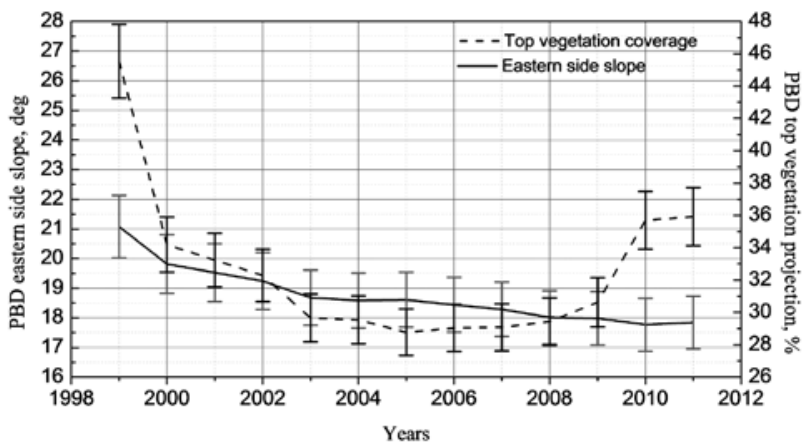

Fig. 6. Changes of the PBD eastern side slope and top vegetation coverage 
change of other PBD morphometric parameters, was impacted by Hurricane Anatoly in 1999 (Jarmalavičius et al. 2011). From 2003 to 2005, the incline of the eastern slope of the PBD stabilized, however, after Hurricane Ervin in 2005, the incline started decreasing again, and the dune was becoming still more inclined and wider (Figs 5, 6). In this way, the sand reserve on the eastern slope of the $\mathrm{PBD}$ was increasing.

The incline change on the PBD's eastern slope, as well as its width, was impacted by projection coverage of vegetation on the top, which has been constantly increasing since 2006. While analysing dependency of the

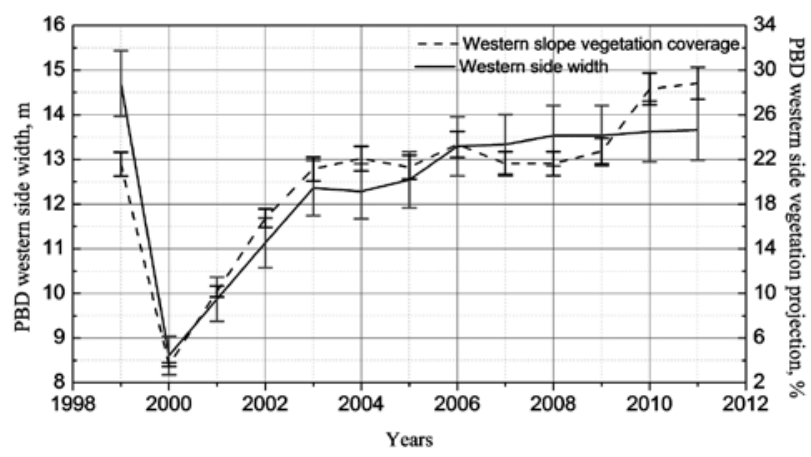

Fig. 7. Changes of the PBD western side width and vegetation coverage

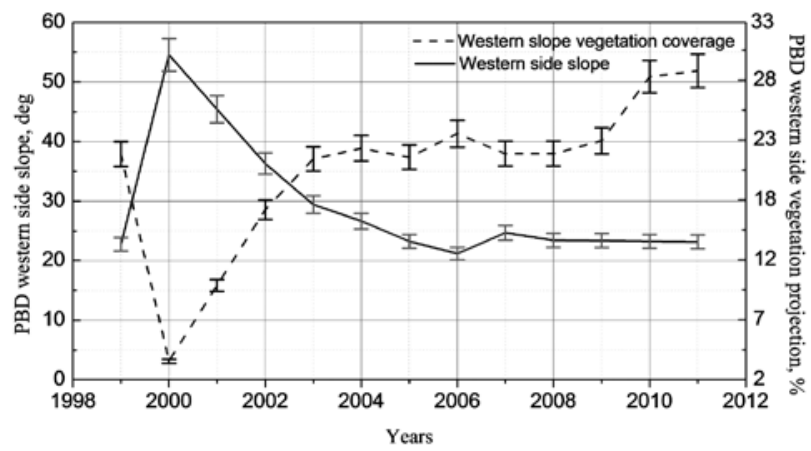

Fig. 8. Changes of the PBD western side slope and vegetation coverage

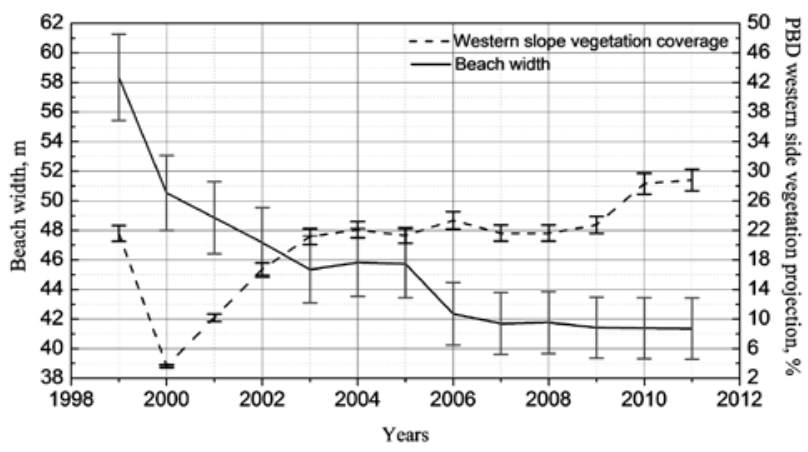

Fig. 9. Changes of beach width and the PBD western side vegetation coverage projection coverage of vegetation of the PBD top and the change of morphometric parameters of the incline of the eastern slope of the $\mathrm{PBD}$, a strong positive correlation was noticed ( $R=0.64)$ (Fig. 6).

On the PBD's western slope the Ammophila arenaria, Leymus arenarius, Lathyrus maritimus, Festuca sabulosa and other plants grow, forming a stable composition of herbaceous vegetation and strongly limiting the transfer of free sand masses onto the western slope of the PBD. The projection coverage of the vegetation on the western slope of the PBD has slightly increased from $21 \%$ to $28 \%$ during the research period. However, after Hurricane Anatoly, due to washed away part of the western slope of the PBD together with vegetation growing on it, the projection coverage of vegetation also decreased down to $3 \%$. Starting from 2003, the situation has been stabilizing and the projection coverage has been increasing every year.

From 1999 to 2011, the width of the western slope of the PBD slightly decreased from $14.7 \mathrm{~m}$ to $13.7 \mathrm{~m}$, however the most significant decrease of the width was after Hurricane Anatoly in 1999 (the width decreased up to $6 \mathrm{~m}$ ). Changes in the incline of the western slope were impacted by the projection coverage of vegetation of the western slope. A very strong correlation $(\mathrm{R}=0.90)$ has been noticed between the projection coverage of vegetation of the western slope of the PBD and morphometric parameters of the width of the western slope of the PBD; thus, it may be presumed that the width of the western slope of the PBD will also remain stable in the future if extreme Anatoly-type hurricanes do not occur again (Fig. 7).

A very strong negative correlation relationship $(\mathrm{R}=$ -0.93 ) exists between the incline of the western slope of the $\mathrm{PBD}$ and the projection coverage of vegetation of the western slope of the PBD. Due to the narrowing western slope of the PBD (Fig. 7), its incline increased (Fig. 8).

The most significant increase of the incline was recorded after Hurricane Anatoly in 1999 when, after washing away a part of the western slope of the PBD, the side of the dune ridge became steeper (it was $22^{\circ}$ in $\mathrm{Au}-$ gust 1999 and $54.5^{\circ}$ after the hurricane). However, due to eolian processes, the incline of the western slope of the PBD returned quickly to the quasi-stable profile and its incline was up to $25^{\circ}$ (Fig. 8).

During the study period, the beach width significantly decreased from $58.3 \mathrm{~m}$ at the beginning of the research to $41.4 \mathrm{~m}$ at the end of the research. These changes were impacted by the highly decreased amounts of sand masses which were being washed away by the sea. Also, changes of the beach width are impacted by the projection coverage of vegetation of the western slope, as it was slightly increasing during the research period. While analysing the projection coverage of vegetation of 
the western slope of the PBD and the change of parameters of the beach width dependent on it, a moderate invert correlation was noticed between these two parameters $(\mathrm{R}=-0.51)$ (Fig. 9).

Therefore, it may be presumed that vegetation is one of the most important environmental factors forming the beach and the PBD in the sandy coasts and that it protects back-dune areas, which are more distant from the coastline, against the movement of free sand masses.

Sediment on the beach, under the effects of hydrodynamic and eolian processes, in the course of time may travel both back to the sea and among the PBD, where it stays for a longer time caught by vegetation, in this way forming new elements of the beach and the dune (Komar 1998). From 1999 to 2011, the beaches of Lithuania withstood the impact of two hurricanes - that of Anatoly in 1999 and Ervin in 2005. The former caused greater damage both to the beach and to the PBD. The impact of Hurricane Anatoly on vegetation is both significant and negative. Due to the washing away of part of the western slope and the top of the PBD, vegetation on them was also destroyed. Consequently, after 1999, the projection coverage of vegetation on the western slope of the PBD has decreased from $21 \%$ to $3 \%$. Furthermore, sediment masses were liberated from the western slope of the PBD, which later on migrated both to the beach, PBD top and the eastern slope of the PBD. Hurricane Ervin in 2005 was different in its power and the prevailing wind direction from that of Anatoly, its damage to the coastline of both the mainland and the Curonian Spit was thus less significant. Also, its negative impact on the projection coverage of vegetation both on the western slope of the PBD and its top was insignificant - the projection coverage of vegetation on these elements of the PBD decreased on average only by $1 \%$. The projection coverage of the eastern slope of the PBD has constantly been slightly increasing; from 1999 to 2009 it ranged from $65 \%$ to $67 \%$ and from 2010 the projection coverage of vegetation has increased up to $73 \%$. The eastern slope of the PBD stabilized and became less affected by eolian processes.

While interpreting the equations of the simple linear regression, it may be suggested that

In the case of the average increase of vegetation of the PBD top by $1 \%$ :

- the beach width would increase on average by 0.73 meters;

- the width of the PBD top would increase on average by 0.26 meters;

- the width of the western slope of the PBD would decrease on average by 0.02 meters;

- The incline of the eastern slope of the PBD would increase on average by $0.13^{\circ}$.
It may be also suggested that in the case of the average increase of vegetation of the western slope of the PBD by $1 \%$ :

- the width of the western slope of the PBD would increase on average by 0.23 meters.

- the incline of the western slope of the PBD would increase on average by $1.41^{\circ}$;

- the beach width would decrease on average by 0.37 meters.

Thus, the presumption that the projection coverage of vegetation impacts the change of the beach width, the width and the incline of the western slope of the PBD, the width of the PBD top and the width of the eastern slope of the $\mathrm{PBD}$ has been proved as there is a very strong, strong and moderate relationship between the projection coverage of vegetation and morphometric parameters of the beach and PBD.

\section{Conclusions}

Projection coverage of vegetation on PBD's morphometric parameters, except beach incline, is medium or very strong. The PBD's western slope vegetation projection coverage has a very strong relationship with the PBD's western slope width $(\mathrm{R}=0.90)$ and incline $(\mathrm{R}=$ -0.93). The PBD top vegetation projection coverage has a medium relationship with beach width $(\mathrm{R}=0.69)$, the PBD top width $(R=0.66)$, and the PBD's eastern slope incline $(R=0.64)$, and a negative medium relationship with the PBD's eastern slope width $(\mathrm{R}=0.64)$. A negative relationship was also noticed between the PBD western slope vegetation projection coverage and beach width $(\mathrm{R}=-0.51)$.

It may be admitted that the projection coverage of vegetation may be used as the PBD's parameter of stability as well as in implementation of integrated coastline zone management. Interpreting the linear regression results, we can suppose that an increase by $1 \%$ of the PBD top vegetation projection coverage, beach width on average will expand by $0.7 \mathrm{~m}$, PBD top width will enlarge by $0.3 \mathrm{~m}$, PBD eastern slope width will decrease just by $0.02 \mathrm{~m}, \mathrm{PBD}$ eastern slope incline will become planer by $0.13^{\circ}$.

An increase in the PBD's western slope vegetation projection coverage by $1 \%$ can cause the PBD's western slope to grow by $0.23 \mathrm{~m}$, the PBD's western slope inline to become steeper by $1.14^{\circ}$, and beach width to become narrower by $0.37 \mathrm{~m}$.

The projection coverage of vegetation has no significant impact, apart from on one of the analysed morphometric parameters of the beach and the PBD - more exactly, the beach incline $(\mathrm{R}=0.23)$, which is directly affected by hydrological parameters. 


\section{Acknowledgements}

The authors are grateful to the Institute of Botany of the Nature Research Centre, Vilnius, Lithuania for their help with plant identification.

\section{References}

Boak, E. H.; Turner, I. L. 2005. Shoreline definition and detection: a review, Journal of Coastal Research 21(4): 688-703. http://dx.doi.org/10.2112/03-0071.1

Buynevich, A.; Bitinas, A.; Pupienis, D. 2007. Reactivation of coastal dunes documented by subsurface imaging of the Great Dune Ridge, Lithuania, Journal of Coastal Research 50: 226-230.

Dailidienè, I.; Davuliene, L.; Tilickis, B.; Stankevičius, A.; Myrberg, K. 2006. Sea level variability at the Lithuanian coast of the Baltic Sea, Boreal Environment Research 11(2): 109-121.

Fontana, S. L. 2005. Coastal dune vegetation and pollen representation in south Buenos Aires Province, Argentina, Journal of Biogeography 32: 719-735.

http://dx.doi.org/10.1111/j.1365-2699.2004.01221.x

Gudžinskis, Z. 1999. Lietuvos induočiai augalai. Vilnius: Botanikos institutas. 209 p.

Heslenfeld, P.; Jungerius, P. D.; Klijn, J. A. 2004. European coastal dunes: ecological values, threats, opportunities and policy development, in M. L. Martinez, N. P. Psuty (Eds.), Coastal dunes: ecology and conservation 171: 335-350. Springer.

Hilton, M. J.; Konlechner, T. M. 2011. Incipient fore dunes developed from marine-dispersed rhizome of Ammophila arenaria, Journal Coast 64: 288-292.

Isermann, M. 2008. Classification and habitat characteristics of plant communities invaded by the non-native Rosa rugosa Thunb. in NW Europe, Phytocoenologia 38(1-2): 133-150. http://dx.doi.org/10.1127/0340-269X/2008/0038-0133

Jarmalavičius, D.; Satkūnas, J.; Žilinskas, G.; Pupienis, D. 2012a. The influence of coastal morphology on wind dynamics, Estonian Journal of Earth Sciences 61(2): 120-130. http://dx.doi.org/10.3176/earth.2012.2.04

Jarmalavičius, D.; Žilinskas, G.; Pupienis, D. 2012b. Impact of Klaipeda port jetties reconstruction on adjacent sea coast dynamics, Journal of Environmental Engineering and Landscape Management 20(3): 240-247.

http://dx.doi.org/10.3846/16486897.2012.660884

Jarmalavičius, D.; Satkūnas, J.; Žilinskas, G.; Pupienis, D. 2011. Dynamics of beaches of Lithuanian coast (the Baltic Sea) for the period 1993-2008 based on morphometric indicators, Environmental Earth Sciences 65(6): 1727-1736. http://dx.doi.org/10.1007/s12665-011-1152-3

Komar, P. D. 1998. Beach processes and sedimentation. PrenticeHall. 544 p.

Łabuz, T. A. 2007. Evaluation of past and present sea holly (Eryngium maritimum) habitats on Polish coastal dunes, Acta Universitatis Latvensis 273: 99-114.

Lekavičius, A. 1989. Vadovas augalams pažinti [Guide to know plants]. Vilnius: Mokslas. 437 p. (in Lithuanian).

Lucas, K. L.; Carter, G. A. 2013. Change in distribution and composition of vegetated habitats on Horn Island, Mississippi, northern Gulf of Mexico, in the initial five years following Hurricane Katrina, Geomorphology 199: 129-137. http://dx.doi.org/10.1016/j.geomorph.2012.11.010
Maun, M. A. 2004. Burial of plants as a selective force in sand dunes, in M. L. Martinez, N. P. Psuty (Eds.), Coastal dunes: ecology and conservation 171: 19-135. Springer.

Mukaka, M. M. 2012. Statistics corner: a guide to appropriate use of correlation coefficient in medical research, Malawi Medical Journal 24(3): 69-71.

NSW Department of Land and Water Conservation 2001. Coastal dune management: a manual of coastal dune management and rehabilitation techniques. Newcastle: Coastal Unit, DLWC.

Olšauskas, A. M. 2009. Woody and grassy vegetation development on different landscape elements of the Curonian Spit, Environment Research, Engineering and Management 50(4): 33-36.

Olšauskas, A. M.; Urboniené, R. 2009. Vegetation development in different landscape element of the Lithuanian mainland seacoast, in Proceedings of the International Scientific Conference: Rural Development, 15-17 October 2009, Akademija, Kaunas region, Lithuania, Rural Development 4(2): 171-175. ISSN 1822-3230.

Povilanskas, R.; Baghdasarian, H.; Arakelyan, S.; Satkūnas, J.; Taminskas, J. 2009. Secular morphodynamic trends of the Holocene dune ridge on the Curonian Spit (Lithuania/Russia), Journal of Coastal Research 25(1): 209-215.

Provoost, S.; Ampe, C.; Bonte, D.; Cosyns, E.; Hoffmann, E. 2002. Ecology, management and monitoring of dune grasslands in Flanders, Belgium, in Littoral 2002, The Changing Coast, 22-26 September 2002, Porto, Portugal. Eurocoast/EUCC, $11-22$.

Remke, E. S.; Blindow, I. 2011. Site specific factors have an overriding impact on Baltic dune vegetation change under low tomoderate $\mathrm{N}$-depositiona case study from Hiddensee Island, Journal of Coastal Conservation 15: 87-97. http://dx.doi.org/10.1007/s11852-010-0123-2

Savukyniene, N.; Moe, D.; Ūsaityte, D. 2003. The occurrence of former heathland vegetation in the coastal areas of the SouthEast Baltic Sea, in particular Lithuania: a review, Vegetation History and Archaeobotany 12(3): 165-175. http://dx.doi.org/10.1007/s00334-003-0008-5

Skeivalas, J. 2001. Metrologiniu ir geodeziniu matavimu apdorojimas [Processing of metrological and geodetic measurements]. Vilnius: Technika. (in Lithuanian).

Snarskis, P. 1968. Vadovas Lietuvos augalams pažinti [Guide to know Lithuanian plants]. Vilnius: Mintis. 502 p. (in Lithuanian).

Stallins, J. A. 2005. Stability domains in barrier island dune systems, Ecological Complexity 2(4): 410-430. http://dx.doi.org/10.1016/j.ecocom.2005.04.011

Stankevičiūte, J. 2006. The succession of sand vegetation at the Lithuanian sea coast, Botanica Lithuanica 12(3): 139-156.

Vilà, M.; Pino, J.; Font, X. 2007. Regional assessment of plant invasions across different habitat types, Journal of Vegetation Science 18(1): 35-42. http://dx.doi.org/10.1111/j.1654-1103.2007.tb02513.x

Walker, D. A.; Epstein, H. E.; Gould, W. A.; Kelley, A. M.; Kade, A. N.; Knudson, J. A.; Krantz, W. B. et al. 2004. Frostboil ecosystems: complex interactions between landforms, soils, vegetation and climate, Permafrost and Periglacial Processes 15: 171-188. http://dx.doi.org/10.1002/ppp.487

Žilinskas, G.; Jarmalavičius, D. 2007. Interrelation of morphometric parameters of the submarine shore slope of the Curonian Spit, Lithuania, Baltica 20(1-2): 46-52. 
Ramunė URBONIENĖ, Lecturer at Landscape Architecture and Environmental Planning Department, Klaipeda University $\mathrm{PhD}$ student in environmental engineering, 20 publications (ISI proceedings - 2); participated in 3 international conferences with oral and poster presentations. Research interests: dynamics of the vegetation scatter of the protective dune, dynamics of the seaside, recreational influence of the protective dune.

Loreta KELPŠAITĖ, Assoc. Prof. Dr. at Geophysical Department, Klaipeda University, PhD in Civil and Environmental Engineering, 11 publications (ISI WOS -7); participated in 20 international conferences with oral and poster presentations, Fellow of the Lithuanian Academy of Science 2010-2011, awarded for the best poster in the section "Conference of Baltic Oceanographers", $7^{\text {th }}$ Baltic Sea Science Congress, 17-21 August 2009, Tallinn, Estonia, Marie Curie Fellow, 2007-2009. Research interests: coastal engineering, wave dynamics, nonlinear interaction, climate change, sediment transport.

Ingrida BORISENKO, Assoc. Prof. Dr. at Computer Science Department, Klaipeda University, PhD in Mathematics, 12 publications (ISI WOS - 1); participated in 11 international conferences with oral and poster presentations. Research interests: statistics, geostatistics, geographic information systems, distance learning. 